senior ophthalmologists who served in the last war and are serving. in the E.M.S. now are too well known to need mention here.

(5) Whether the service of a younger man is to be an unlimited offer to serve in H.M. Forces anywhere or to be a limited offer of local service in the E.M.S. is entirely a matter for the individual conscience and is no part of the Services case. Nor does the extent of service in the E.M.S. concern the military oculist overseas and any idea that there is general mistrust in the Services on this account is mischievous and plain nonsense to those of us who are in touch with our E.M.S. friends, or with patients whom we have sent home. No serviceman overseas would presume to judge a situation of which he has little more than fragmentary knowledge.

(6) However, now that the emergency is less it is accepted by all responsible sections of the medical profession that speedy relief is justly due to those who have served abroad for some time in order that the sacrifice of domestic upheaval may be shared.

(7) The prior need of the Army in war is, and always has been, for ophthalmologists of ripe surgical experience, and this need will become more acute as demobilisation of senior and older men of long service proceeds. At present, owing to lack of replacements, Army ophthalmologists who have already completed over two years service abroad are having to be despatched for still more foreign service. Is it not logical that questioning eyes are now looking towards home?

(8) Special arrangements for exchange bristle with difficulties of administration which would inevitably cause delay: they are not now really required. Ordinary recruitment and demobilisation. should be sufficient to continue to give our Forces in the Far East what is their due-a first-class ophthalmic organisation. To return to your vineyard, Sirs : would it not be as well for all of us now to reflect on Matthew XXI, verses 28-31?

Yours faithfully,

B. W. RYCROFT.

Lt.-Col., R.A.M.C.

ALLIED FORCE HEADQUARTERS,

OFFICE OF THE SURGEON, C.M.F.

July 5,1945 .

\title{
INTRA-OCULAR FOREIGN BODY LOCALISATION
}

To the Editors of THE BRITISH JOURNAL OF OPHTHALMOLOGY.

DEAR SIRS,-I was interested to read Major Skeoch's article on the use of an "equatorial ring" in the localisation of intra-ocular foreign bodies in the March number of the Journal. As the accurate localisation of the I.O.F.B. plays an important part in ophthalmic war surgery any additional method demands careful study. 
The "limbal ring" (following Major H. B. Stallard's classical 'description in the Journal for March 1944), is in routine use in my department, and I am writing to suggest that it retains several important advantages over the "equatorial ring."

1. The Direct Lateral X-ray View.-Since, as Major Skeoch states, the "equatorial ring" does not fit the exact equator the relationship it bears to the anterior and posterior pole of the globe is not known. Thus a circle, corresponding to the diameter of the eye, cannot be superimposed accurately on the X-ray plate and the relationship that this bears to the F.B. be assessed. This valuable relationship can, however, be established when using the "limbal ring."

Major Skeoch says nothing in his article regarding the use of double-exposure, i.e., taking two $\mathrm{X}$-ray exposures on the same plate, one with the eye looking up and the other with it looking down. To obtain absolute immobility of the head during these exposures a clamp is used as devised by Lt.-Col. Lawler (Adviser in Radiology, S.A.), to whose assistance in this work I am much indebted. This is a very valuable procedure, for any $F$. B. that appears twice and that on both exposures bears the same relationship to each "limbal ring" must be moving with the globe and its position, in relationship to the known position of the ring can be measured. This procedure is at its most valuable when there are multiple F.Bs. present in the orbit. When using the "equatorial ring" the movement of the ring being so small and the exact position of the ring in relationship to the globe not being known, the information obtained from the apparent movement of an F.B. is much less valuable.

2. The Anterior-posterior X-ray View.-Here, again, since the ring does not fit the equator accurately, the F.B. while appearing to lie inside the ring and therefore inside the globe may actually be extra-ocular.

It is realised that the "equatorial ring" has two great advantages which give it an immediate appeal, that of simplicity in insertion and that of non-irritation in an inflamed eye. The sewing in position of the "limbal ring " is an operation in itself and although I have not known it to effect adversely an inflamed eye it might well do so.

In view, however, of the above, I consider that the advantages of the "limbal ring" in localisation as compared to the "equatorial ring" are such as to make a change to the use of the latter of questionable value.

Yours faithfully,

L. B. Somerville-Large, Lt.-Col., R.A.M.C.

OPHTHALMIC DEPARTMENT, Adviser in Ophthalmology. S.A. SECUNDERABAD, INDIA. July 4, 1945. 